\title{
Behavior of the effective heat transfer coefficient and global thermal resistance in freezing of fruit juice model solutions in cylindrical packages
}

\author{
Cristina Guimarães PEREIRA ${ }^{1}$ (D), Jaime Vilela de RESENDE ${ }^{1 *}$
}

\begin{abstract}
In this study the effect of packing on freezing time, effective heat transfer coefficient and global thermal resistance were evaluated during the freezing of fruit juice model solution in an air blast freezer. Two configurations were arranged with 40 buckets and $15 \mathrm{~kg}$ of solution in each, totaling $600 \mathrm{~kg}$. Thermocouples were installed to monitor the temperature profiles within the solution and at the packaging and cooling air surface. The temperature data were used to calculate the effective heat transfer coefficients and the resistances throughout the freezing process. The use of metal buckets represented reductions of up to $19.60 \%$ in the freezing times. Also, the temperature curve plateau, characterizing solidification (phase change period), was reduced. The main result of this paper was the possibility of calculating the effective heat transfer coefficients and global thermal resistances during the complete process of freezing. These properties assumed different values, not having a constant distribution throughout the freezing process.
\end{abstract}

Keywords: effective heat transfer coefficient; freezing tunnel; global thermal resistance; heat transfer.

Practical Application: Effective heat transfer coefficient and global thermal resistance of model solution.

\section{Introduction}

The freezing of food inside freezing tunnels is a process based on a simultaneous heat and mass transfer between the food and the air flow. From an engineering viewpoint, the freezing process is an unsteady-state heat transfer phenomenon in which the food loses heat by convection through its surface and by conduction in its interior (Rahman, 2009).

One important factor to be considered during food freezing is the packaging material. That with low thermal resistance would be of interest since it allows faster heat exchange between the packaging material and the food. According to Santos et al. (2008) it is difficult to decompose the different heat transfer resistances quantitatively during freezing. This is due to the complexity of the interfaces between the product and the packaging, the gap between the primary and secondary packaging, as well as the thermal contact resistances.

The process of freezing is considered to be of great interest for industrialized food, as it provides long term food conservation, maintaining most of its original characteristics, adding value to the food and contributing to loss reduction (Pereira et al., 2017). However, food freezing is a phase change heat transfer problem, with consequent changes in properties such as specific heat, enthalpy, and thermal conductivity, during the conversion of water into ice (Jie et al., 2003; Santos et al., 2008). The process does not happen at a constant temperature, but over a temperature range depending on the food composition and structure, its physical geometry, initial freezing temperature, and operational conditions (American Society of Heating Refrigerating and Air Conditioning Engineers, 2006). In addition, an important parameter, the convective heat coefficient, does not have a constant distribution throughout the freezing process (Pereira et al., 2017) and it can have different values according to the packaging material used during the food freezing.

The simulation of the performance of a freezing system is required for its design, adaptation and operation. Therefore, accurate knowledge of the heat transfer coefficients and the understanding of the thermal resistance created by the packaging material are essential in order to obtain a reliable prediction. However, these parameters are often too complex to be estimated under industrial processing conditions such as in a freezing tunnel (Amarante \& Lanoisellé, 2005; Santos et al., 2008).

The aim of this work was to study the heat transfer process during the freezing of fruit juice model solution stored in buckets made of different materials (metal and plastic); to calculate the experimental effective heat transfer coefficients and the global thermal resistance throughout the freezing process.

\section{Materials and methods}

\subsection{Model solution preparation and experimental setup}

A model solution was used to simulate fruit juices. For the experiment, a $600 \mathrm{~kg}$ solution was prepared which consisted of $0.5 \% \mathrm{k}$-carrageenan (weight/volume in water) and $10 \%$ sucrose (weight/volume in water). The k-carrageenan was added to increase the viscosity and to avoid convection processes within the solution and the sucrose used could simulate fruit juice/pulp (Pereira et al., 2017). According to Saad \& Scott (1994), sucrose is the regular sugar present in various food products, including 
the fruit juices. Such products exhibit a variety of total soluble solids content and the concentration of $10 \%$ sucrose was chosen for being a representative average value of the total soluble solids content of various tropical fruit juices (Brasil, 2000), as shown in the Table S1 (Supplementary Material).

The cooling and freezing of the solution were carried out in an air blast freezer under controlled condition at $-25^{\circ} \mathrm{C}$. The air velocity was measured with the aid of a hot wire anemometer (TSI - Model 9535 - TSI Incorporated, USA) installed in front of the evaporator outlet. The operation conditions indicated a highest air velocity of $2.54 \mathrm{~m} . \mathrm{s}^{-1}$.

The load consisted of using 40 buckets distributed in 2 lines as shown in Figure 1. The positioning was done in the central part of the air blast freezer.

The buckets were $38 \mathrm{~cm}$ in height and $30 \mathrm{~cm}$ in diameter. Each bucket contained $15 \mathrm{~kg}$ of the fruit juice model solution.

A first configuration was established consisting of the use of high density polyethylene buckets (HDPE). For the second configuration, two plastic buckets were replaced by metal buckets. Temperature sensors were positioned at these two buckets for data acquisition.

\subsection{Monitoring of solution, air and packaging surface temperatures}

Temperature profiles were obtained with 7 temperature sensors (type T thermocouple copper/constantan AWG-24 and resistive thermal devices - RTDs). Two sensors were used for monitoring the surface temperature of buckets 1 and 2 (showed in Figure 1); and other two were used for monitoring the temperature of the solution present in the same buckets, being positioned at the center of the solution mass. Three parallel arrangements of type- $\mathrm{T}$ thermocouples were distributed evenly in front of and behind the evaporator and near the tunnel floor in order to monitor the average temperature of the cooling air.

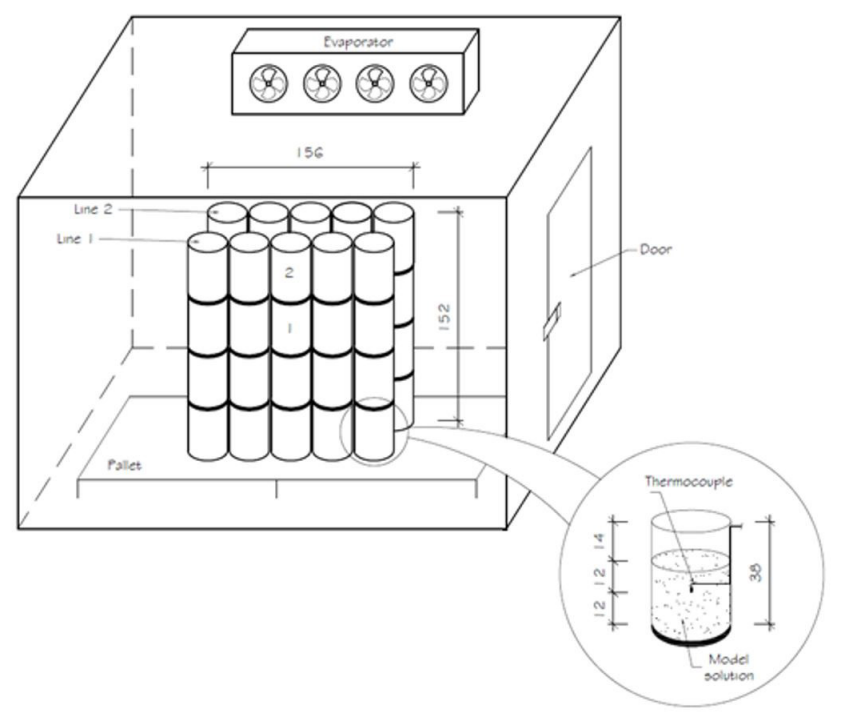

Figure 1. Placement of buckets and their internal detail containing the model solution and the thermocouple in the center of the solution mass.
The sensors were connected to a signal conditioning system (National Instruments - Model SCXI - Hungary) and the temperature measurements were obtained at $5 \mathrm{~min}$ intervals using the LabVIEW 8.5 software.

\subsection{Determination of enthalpy and specific heat}

Enthalpy and specific heat measurements were made using a differential scanning calorimeter (DSC) (DSC Q100, TA Instruments Inc., New Castle, DE) with a liquid nitrogen cooling system. Prior to sample measurements, the DSC was calibrated using a sapphire standard. The DSC measurements were made using $10 \mathrm{mg}$ of solution which was placed in hermetically sealed aluminum pans. An empty pan was used as a reference. To evaluate the enthalpy, the methodology consisted of establishing the sample at $-23^{\circ} \mathrm{C}$, then conducting a DSC scan at a heating rate of $2{ }^{\circ} \mathrm{C} / \mathrm{min}$ until reaching $25^{\circ} \mathrm{C}$. With the enthalpy results obtained for every degree change in the temperature it was possible to determine the specific heat by Equation 1.

$c_{p}=\Delta H_{p} / \Delta T$

where: $\mathrm{c}_{\mathrm{p}}=$ specific heat $\left(\mathrm{kJ} \cdot \mathrm{kg}^{-1} \cdot{ }^{\circ} \mathrm{C}^{-1}\right) ; \Delta \mathrm{H}_{\mathrm{p}}=$ enthalpy variation $\left(\mathrm{kJ}^{\mathrm{k}} \mathrm{kg}^{-1}\right) ; \Delta \mathrm{T}=$ temperature variation $\left({ }^{\circ} \mathrm{C}\right)$.

\subsection{Determination of the initial freezing temperature of the model solution}

The initial freezing point was determined by cooling curve methodology (Rahman, 2009), considered to be one of the most simple, accurate and widely used methods to measure this parameter in foods.

\subsection{Calculation of the effective heat transfer coefficient $\left(h_{\text {eff }}\right)$}

To evaluate the effective heat transfer coefficients $\left({ }_{\text {heff }}\right)$, an energy balance was used according to Pereira et al. (2017), using Equations 2 and 3. The effective temperature difference between the surface of the bucket $\left(\mathrm{T}_{\mathrm{bc}}\right)$ and the air $\left(\mathrm{T}_{\text {air }}\right)$ during a time interval $\Delta \mathrm{t}$ is given by Equation 4 .

$$
\begin{aligned}
& \mathrm{m}_{\mathrm{bc}} \mathrm{c}_{\mathrm{pbc}} \mathrm{dT}_{\mathrm{bc}} / \mathrm{dt}+\mathrm{m}_{\mathrm{sol}} \mathrm{c}_{\mathrm{psol}} \mathrm{dT}_{\mathrm{sol}} / \mathrm{dt}=\mathrm{h}_{\mathrm{eff}} \mathrm{A}\left(\mathrm{T}_{\mathrm{bc}}-\mathrm{T}_{\text {air }}\right) \\
& \mathrm{h}_{\mathrm{eff}}=\left(\left(\mathrm{mc}_{\mathrm{p}} \Delta \mathrm{T}\right)_{\mathrm{bc}}+\left(\mathrm{mc}_{\mathrm{p}} \Delta \mathrm{T}\right)_{\mathrm{sol}}\right) / \mathrm{A}\left(\mathrm{T}_{\mathrm{bc}}-\mathrm{T}_{\mathrm{air}}\right) \Delta \mathrm{t} \\
& \mathrm{T}_{\mathrm{bc}}-\mathrm{T}_{\mathrm{air}}=\left[\left(\mathrm{T}_{\mathrm{bc}}(\mathrm{t})+\mathrm{T}_{\mathrm{bc}}(\mathrm{t}+\Delta \mathrm{t})\right) / 2\right]-\left[\left(\mathrm{T}_{\mathrm{ar}}(\mathrm{t})+\mathrm{T}_{\text {air }}(\mathrm{t}+\Delta \mathrm{t})\right) / 2\right]
\end{aligned}
$$

where: $\mathrm{A}=$ heat transfer area $\left(\mathrm{m}^{2}\right) ; \mathrm{m}_{\mathrm{bc}}$ and $\mathrm{m}_{\mathrm{sol}}=$ mass of the empty bucket and the solution, respectively $(\mathrm{kg}) ; \mathrm{c}_{\mathrm{pbc}}$ and $\mathrm{c}_{\mathrm{psol}}=$ specific heat of the solution and the bucket, respectively $\left(\mathrm{kJ} \cdot \mathrm{kg}^{-1} \cdot{ }^{\circ} \mathrm{C}^{-1}\right)$; $\mathrm{T}_{\mathrm{bc}}, \mathrm{T}_{\mathrm{sol}}$ and $\mathrm{T}_{\mathrm{air}}=$ temperatures of the bucket, solution and air, respectively $\left({ }^{\circ} \mathrm{C}\right)$.

The specific heat values of the plastic buckets and metal buckets were 2.3012 and $0.444 \mathrm{~kJ}_{\mathrm{kg}}{ }^{-1} \cdot \mathrm{C}^{-1}$, respectively, taken according to specifications of the manufacturer and data reported in Incropera et al. (2000). 


\subsection{Effect of packaging on freezing time and global thermal resistance to heat transfer}

A study was carried out in order to evaluate the differences in terms of freezing time and global thermal resistance to heat transfer with the use of the two packages (plastic and metal).

The packages affect the heat transfer coefficients of food since they promote its insulation, causing a barrier to energy transfer, and can create voids filled with air that end up reducing the effective heat transfer coefficient and change the energy exchange in the system.

The freezing time was evaluated through the thermocouples positioned at the center of the solution mass present in buckets 1 and 2 (shown in Figure 1). The end of freezing time was defined when reaching $-18{ }^{\circ} \mathrm{C}$.

The global thermal resistance to heat transfer was evaluated according to Equations 5 and 6 (Santos, 2005).

$\mathrm{R}_{\text {total }}=\mathrm{T}_{\text {sol }}-\mathrm{T}_{\text {air }} / \mathrm{q}$

$\mathrm{q}=\left[\left(\mathrm{mc}_{\mathrm{p}} \Delta \mathrm{T}\right)_{\mathrm{bc}}+\left(\mathrm{mc}_{\mathrm{p}} \Delta \mathrm{T}\right)_{\mathrm{sol}}\right] / \Delta \mathrm{t}$

$\mathrm{T}_{\text {sol }}-\mathrm{T}_{\text {air }}=\left[\left(\mathrm{T}_{\text {sol }}(\mathrm{t})+\mathrm{T}_{\text {sol }}(\mathrm{t}+\Delta \mathrm{t})\right) / 2\right]-\left[\left(\mathrm{T}_{\text {air }}(\mathrm{t})+\mathrm{T}_{\text {air }}(\mathrm{t}+\Delta \mathrm{t})\right) / 2\right]$

where: $\mathrm{R}_{\text {total }}=$ global thermal resistance to heat transfer $\left({ }^{\circ} \mathrm{C} / \mathrm{W}\right) ; \mathrm{m}_{\mathrm{bc}}$ and $\mathrm{m}_{\mathrm{sol}}=$ mass of the empty bucket and the solution, respectively $(\mathrm{kg}) ; \mathrm{c}_{\mathrm{pbc}}$ and $\mathrm{c}_{\mathrm{psol}}=$ specific heat of the solution and the bucket, respectively $\left(\mathrm{kJ} \cdot \mathrm{kg}^{-1} .{ }^{\circ} \mathrm{C}^{-1}\right) ; \mathrm{T}_{\mathrm{bc}}, \mathrm{T}_{\mathrm{sol}}$ and $\mathrm{T}_{\mathrm{air}}=$ temperatures of the bucket, solution and air, respectively $\left({ }^{\circ} \mathrm{C}\right) ; \mathrm{t}=$ time $(\mathrm{sec})$.

\section{Results and discussion}

\subsection{Enthalpy and specific heat}

The evolution of enthalpy and specific heat is shown as a function of temperature in Figure 2. The temperature ranged from -23 to $25^{\circ} \mathrm{C}$.

From Figure 2A it can be observed that overall, the enthalpy change during thawing, as a consequence of the proportion of freezable and unfreezable water for each temperature. According to Rao et al. (2014) water is a component of foods that exhibits solidification/melting phase transition and presents a very high enthalpy of melting.

In the case of the specific heat there is a sharp increase in its value around the initial freezing point $\left(-1.1^{\circ} \mathrm{C}\right)$, characterizing the latent heat release. According to Rao et al. (2014), in foods, which are complex "impure" substances, the latent heat is not released or absorbed at one well defined temperature (as in very pure substances), but over a range of temperatures.

\subsection{Initial freezing temperature of the solution}

Figure 3 presents the initial freezing temperature $\left(\mathrm{T}_{\mathrm{if}}\right)$ of the model solution, which was obtained through cooling curve measurements performed in triplicate.
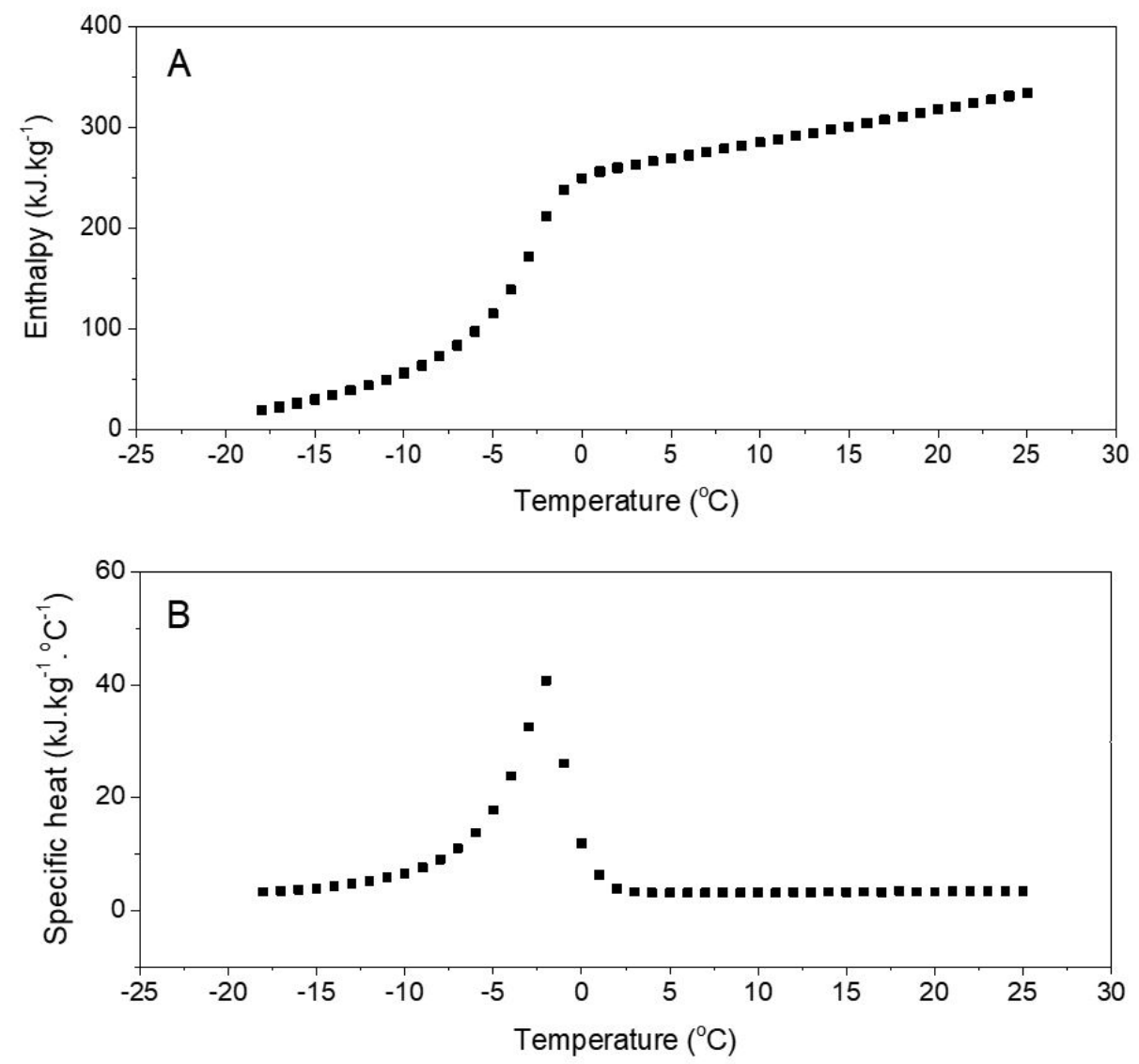

Figure 2. Enthalpy (A) and specific heat (B) of the model solution for the temperature range from $\left(-23\right.$ to $\left.25^{\circ} \mathrm{C}\right)$. 
In Figure 3 the supercooling phenomenon can be observed, defined as cooling below the initial freezing point of a sample without ice being formed. It ends when there is the formation of initial ice crystallization, charactering the beginning of the phase change period and therefore marking the initial freezing temperature (Rahman, 2009). The same author emphasizes that cooling rate, volume and amount of solute are some of the several factors involved in the tendency of a system to provide supercooling.

According to Pham (2006) some degree of supercooling can be observed in most food freezing processes, where the surface dips briefly below the freezing point before suddenly coming up to the freezing temperature.

For the three runs performed in our work different intensities of supercooling were observed, which may be explained by the fact of not having used the same amount of samples and non-uniform cooling rate which did not generate losses or alterations in the determination of the initial freezing point. Fellows (2009) reported that the supercooling can reach up to $10^{\circ} \mathrm{C}$ below the food freezing.

In Figure 3, the initial freezing temperature was taken as the temperature after supercooling at the beginning of a substantially constant temperature plateau. The average obtained for $\mathrm{T}_{\mathrm{fs}}$ was $-1.134^{\circ} \mathrm{C} \pm 0.027^{\circ} \mathrm{C}$.

\subsection{Freezing time of the solution}

Figure 4 shows the cooling curves of the model solutions present in the metal bucket and in the plastic bucket for the configuration at the top and on the side of the freezing tunnel. In addition, the reference temperature is present (red line at $-18^{\circ} \mathrm{C}$ ), which was taken as the freezing temperature of the system. According to Ramaswamy \& Tung (1984), the most frequently used definitions of the freezing time are the thermal arrest time or the duration of the freezing process from start to finish, both representing the time needed to traverse a range of temperature. In this work, the freezing time was recorded from the time that the tunnel was connected until the moment when all thermocouples installed within the solution reached $-18^{\circ} \mathrm{C}$. This temperature was chosen for being the most commonly used temperature for commercially frozen food (Delgado \& Sun, 2001).

By analyzing the curves present in Figure 4 it can be seen that the freezing times demonstrated in the metal buckets were always lower than those obtained with the plastic buckets, at the top and side of the freezing tunnel. At the top, the difference in the freezing times using the different materials were 8.41 and 9.50 hours, for repetition 1 (Figure 4A) and 2 (Figure 4B), respectively. The use of metal buckets represented an average processing time reduction of approximately $19.60 \%$. Furthermore, the freezing in the metal buckets brought a decrease in the characteristic phase change region of the solution (phase change period) when compared to the use of plastic buckets. This region can be taken from the beginning of the substantially constant temperature plateau until the moment that the temperature starts decreasing again (tempering period). This fact led to a reduction in the freezing time. Such a difference in freezing time may be explained by the fact that the plastic buckets had a lid and the metal were

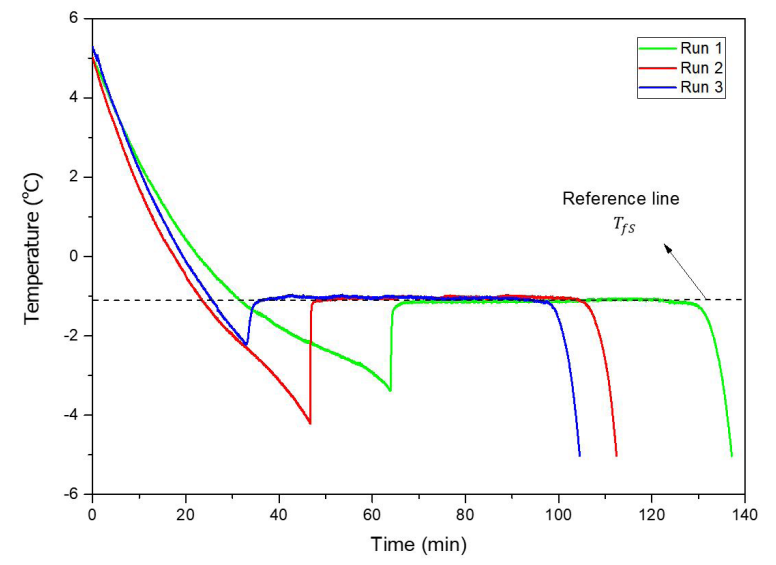

Figure 3. Cooling curves for determination of the initial freezing temperature of the model solution.
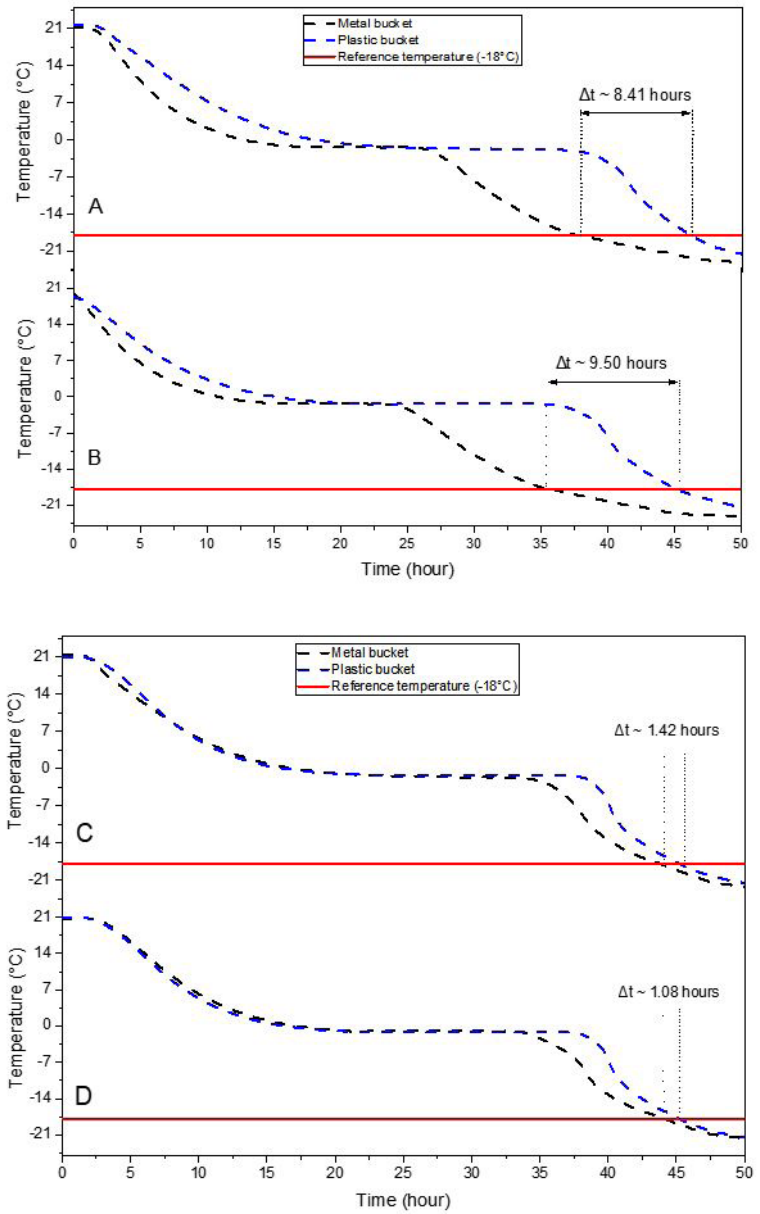

Figure 4. Cooling curves of the model solution present in the buckets positioned on the top (A and $B$ ) and on the side (C and D).

uncovered. Thus cooling air could come in direct contact with the solution being frozen, providing a faster freeze. At the top of the tunnel, the lid area of the buckets was that which had the most contact with the cooling air (Figure 1), so the use of the lid generated a large difference in the time taken to freeze the solution. 
By analyzing the temperature data from the bucket positioned along the side of the tunnel (Figure 4C and 4D), it can be observed that the freezing times for metal and plastic configurations are very similar, with an average difference of 1.25 hours. In this situation, the cooling air came in direct contact with the side of the two materials (plastic and metal), and the differentiation in the freezing time is primarily due to the greater ease of the metal in conducting heat compared to the plastic.

Santos et al. (2008), in a study with cooling and freezing of cuts of chicken in convective tunnels observed reductions of up to $45 \%$ in the freezing time of the products when using metallic mesh boxes compared to carton boxes.

For a better evaluation of the differences in freezing time, a study regarding the global thermal resistance to heat transfer was done. Figure 5 shows the behavior of the global thermal resistances with the processing time in the metal bucket configurations and in the plastic bucket configurations.

Figure 5 presents that the averages of the global thermal resistance observed in the measurements with metallic buckets (Figure 5A and 5B) were lower than in the experiment performed with the plastic buckets (Figure 5C and 5D). This behavior characterizes greater ease in the heat transfer when materials with high thermal conductivity, such as the metallic buckets, are used. According to Incropera et al. (2000), in the case of the metal buckets (material with high heat transfer rate), their internal thermal resistance could be neglected when compared to the heat transfer resistance between the tunnel air and the outer surface of the bucket. Therefore, it could be considered that practically all the temperature difference in the system occurs between the metal bucket and the air that surrounds it.

Santos (2005) also evaluated the parameter of the thermal resistance in an air blast freezing tunnels. He observed that when a galvanized steel tank was cover by a corrugated cardboard packaging, resistance values increased from 0.18 to $0.50^{\circ} \mathrm{C}^{\mathrm{W}} \mathrm{W}^{-1}$.

In both, metallic and plastic buckets, the global thermal resistances obtained in the precooling period were higher than those calculated for the tempering period. Such behavior can be explained in terms of the different thermal conductivities of the model solution when it is thawed and frozen. According to Carson (2006) the conductivity of the ice is about four times higher than the liquid water. Also, according to Santos et al. (2008) the heat resistance to heat conduction is inversely proportional to the thermal conductivity of the material.

Figure 6 shows the effective heat transfer coefficients obtained by temperature measurements performed on the metal bucket 1 (side position) and 2 (top position) (Figure 1).

To calculate the average effective coefficient, the values used were only those obtained in the phases of precooling and tempering period. Values obtained during the phase change were discarded due to the sharp increase in specific heat (latent heat release), which could generate unambiguous results in the effective heat transfer coefficient. According to Belchior et al. (2014), below the initial freezing point, the heat transfer coefficients values go through extreme variations and cannot be deduced properly using the energy balance applied in this work.
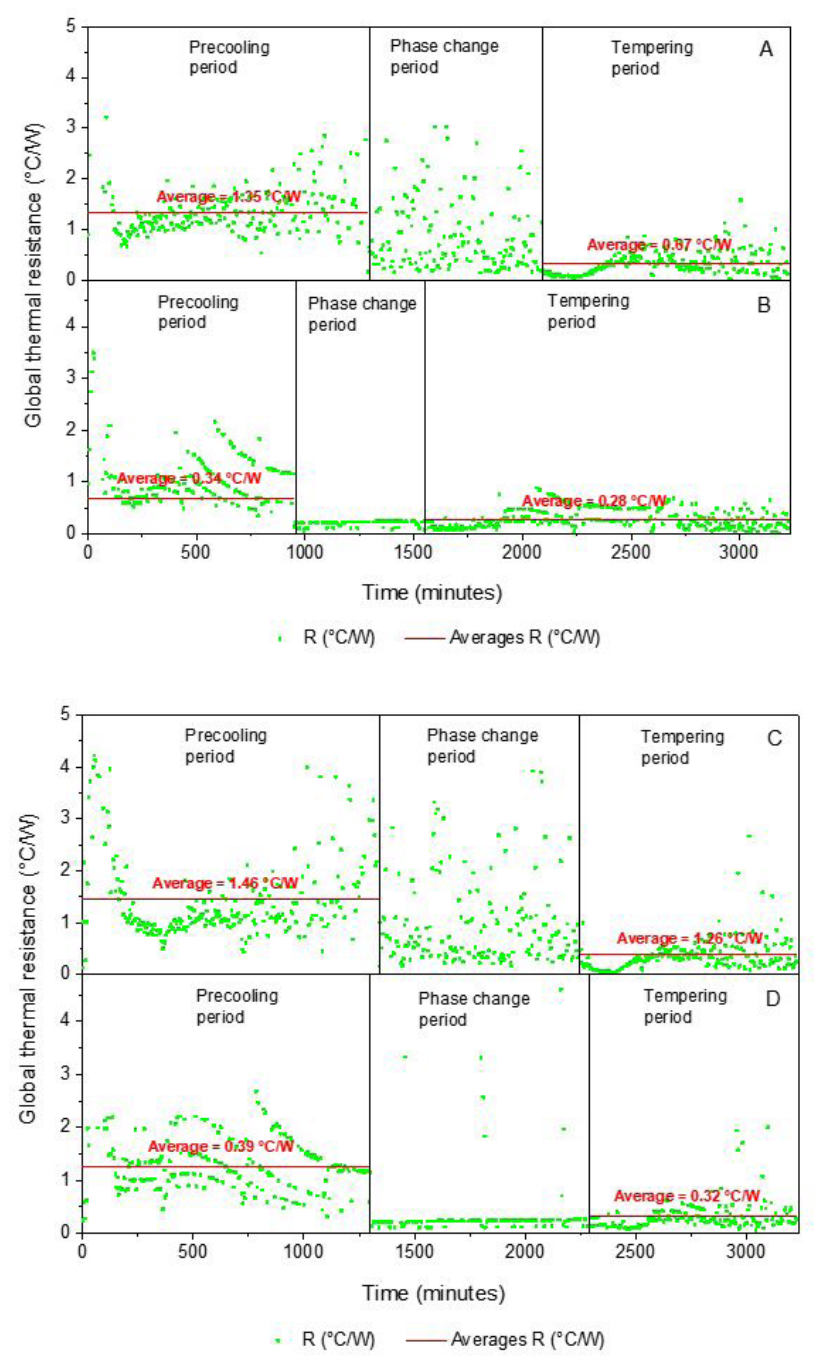

Figure 5. Values of the global thermal resistances obtained during freezing of the solution in the configuration with metallic buckets (A - Side and B - Top) and with plastic buckets (C - Side and D - Top).

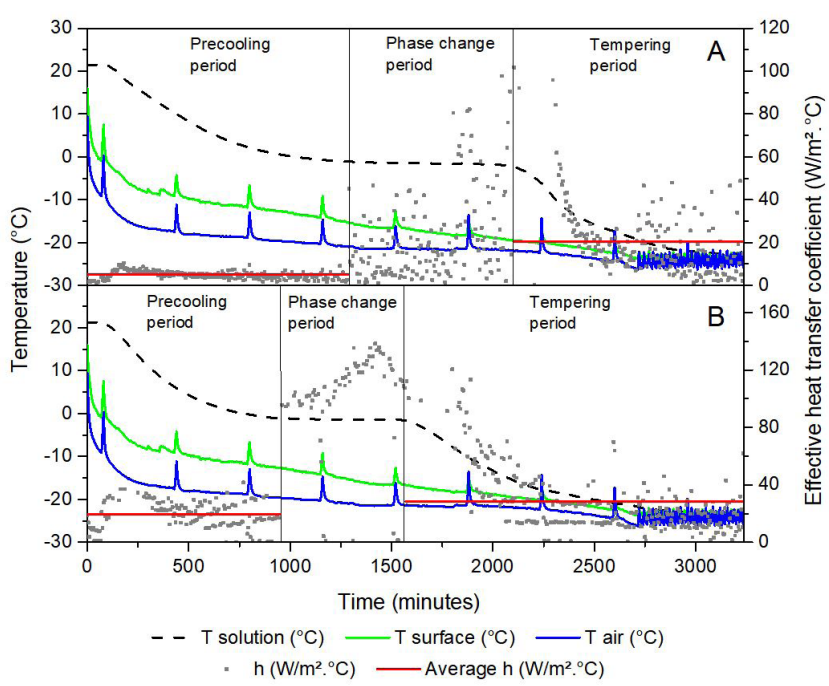

Figure 6. Temperature profiles (solution, surface and air), effective heat transfer coefficients and their average (in the precooling period and tempering period). (A) For the side configuration; and (B) for the top configuration. 
Table 1. Mean convective coefficients (precooling and tempering period) on the side and top of metal bucket configurations.

\begin{tabular}{ccc}
\hline \multirow{2}{*}{ Position } & \multicolumn{2}{c}{ Mean effective heat transfer coefficient $\left(\mathrm{W} \cdot \mathrm{m}^{-2} \cdot{ }^{\circ} \mathrm{C}^{-1}\right)$} \\
\cline { 2 - 3 } & Precooling period & Tempering period \\
\hline Side & 5.06 & 20.38 \\
Top & 19.26 & 28.35 \\
\hline
\end{tabular}

Figure 6 shows that during the cooling/freezing of the solution the effective heat transfer coefficients assumed different values, a distribution of which, throughout the freezing process, was not constant. The average values obtained for the effective coefficients are presented in the Table 1.

During the tempering period, the mean effective coefficient values were higher than those in the precooling period, for both positions, mostly because of carryover effects of the phase change period. Furthermore, once in the tempering period the solution is already completely frozen, the water present is in the form of ice that has a higher thermal conductivity than that of liquid water, resulting in better heat transfer within the solution.

Regarding the position, the average values of the coefficients were different when measured on the side and on top of each configuration. The values from the top always showed to be higher. This difference may be related to the higher values of air velocity at the top of the freezing tunnel, since bucket 1 was near the evaporator (Figure 1).

\section{Conclusions}

This work allowed the understanding of the heat transfer dynamics process during freezing of fruit juice model solutions in a freezing tunnel. It was possible to evaluate the effective heat transfer coefficients and global thermal resistance created by the packaging material throughout the freezing process.

The tests carried out demonstrated, experimentally, that the use of metal buckets represented reductions of up to $19.60 \%$ in the freezing times. Also, the plateau of the temperature curve characterizing solidification (phase change period) was reduced using metal buckets.

During the cooling/freezing of the model solution the effective heat transfer coefficients assumed different values, for which a distribution throughout the freezing process was not constant. For the tempering period, the values were higher than those in the precooling period, mostly because of carryover effects of the phase change period. On the other hand, regarding the global thermal resistances, the data values obtained in the precooling period were higher than those calculated for the tempering period. This could be explained in terms of the different thermal conductivities of the model solution when it is thawed and frozen.

The main result of this paper was the possibility of calculating the effective heat transfer coefficients and global thermal resistances during the complete process of freezing, hence these parameters could be evaluated in the three cooling periods (precooling, phase change and tempering).

\section{Acknowledgements}

This study was financed in part by the Coordenação de Aperfeiçoamento de Pessoal de Nível Superior - Brazil (CAPES) Finance Code 001. The authors wish to thank the Fundação de Amparo à Pesquisa do Estado de Minas Gerais (FAPEMIG- Brazil) and Conselho Nacional de Desenvolvimento Científico e Tecnológico (CNPq - Brazil) for financial support for this research.

\section{References}

Amarante, A., \& Lanoisellé, J.-L. (2005). Heat transfer coefficients measurement in industrial freezing equipment by using heat flux sensors. Journal of Food Engineering, 66(3), 377-386. http://dx.doi. org/10.1016/j.jfoodeng.2004.04.004.

American Society of Heating Refrigerating and Air Conditioning Engineers - ASHRAE. (2006). Handbook of refrigeration. Atlanta: ASHRAE.

Belchior, N. C., Oliveira Giarola, T. M., \& Resende, J. V. (2014). Effects of airflow induction on heat transfer and energy consumption while freezing passion fruit pulp in stacked boxes. Energy Efficiency, 7(5), 777-790. http://dx.doi.org/10.1007/s12053-014-9253-y.

Brasil. (2000, January 7). Regulamento técnico geral para fixação dos padrões de identidade e qualidade para polpa de fruta (Instrução normativa ${ }^{\circ} 1$, de 7 de janeiro de 2000). Diário Oficial [da] República Federativa do Brasil.

Carson, J. K. (2006). Review of effective thermal conductivity models for foods. International Journal of Refrigeration, 29(6), 958-967. http:// dx.doi.org/10.1016/j.ijrefrig.2006.03.016.

Delgado, A. E., \& Sun, D.-W. (2001). Heat and mass transfer models for predicting freezing processes: a review. Journal of Food Engineering, 47(3), 157-174. http://dx.doi.org/10.1016/S0260-8774(00)00112-6.

Fellows, P. J. (2009). Food processing technology: principles and practice. Duxford: Elsevier. http://dx.doi.org/10.1533/9781845696344.

Incropera, F. P., DeWitt, D. P., Bergman, T. L., \& Lavine, A. S. (2000). Fundamentos de transferência de calor e de massa. Rio de Janeiro: Grupo Gen-LTC.

Jie, W., Lite, L., \& Yang, D. (2003). The correlation between freezing point and soluble solids of fruits. Journal of Food Engineering, 60(4), 481-484. http://dx.doi.org/10.1016/S0260-8774(03)00081-5.

Pereira, C. G., Ramaswamy, H. S., Giarola, T. M. de O., \& de Resende, J. V. (2017). Infrared thermography as a complementary tool for the evaluation of heat transfer in the freezing of fruit juice model solutions. International Journal of Thermal Sciences, 120(4), 386-399. http://dx.doi.org/10.1016/j.ijthermalsci.2017.06.025.

Pham, Q. T. (2006). Modelling heat and mass transfer in frozen foods: a review. International Journal of Refrigeration, 29(6), 876-888. http:// dx.doi.org/10.1016/j.ijrefrig.2006.01.013.

Rahman, M. S. (2009). Food properties handbook. Boca Raton: CRC Press. http://dx.doi.org/10.1201/9781420003093.

Ramaswamy, H. S., \& Tung, M. A. (1984). A review on predicting freezing times of foods. Journal of Food Process Engineering, 7(3), 169-203. http://dx.doi.org/10.1111/j.1745-4530.1984.tb00302.x.

Rao, M. A., Rizvi, S. S. H., Datta, A. K., \& Ahmed, J. (2014). Engineering properties of foods. Boca Raton: CRC press.

Saad, Z., \& Scott, E. P. (1994). Estimation of temperature dependent thermal properties of basic food solutions during freezing. American Society of Mechanical Engineers, Heat Transfer Division, 286, 47-51.

Santos, C. Á. (2005). Estudo da transferência de calor durante o congelamento de cortes de aves em caixas de papelão ondulado (Dissertação de mestrado). Universidade Federal de Santa Catarina, Florianópolis.

Santos, C. Á., Laurindo, J. B., Silveira, V. Jr., \& Hense, H. (2008). Influence of secondary packing on the freezing time of chiken meat in air blast freezing tunnels. Food Science and Technology, 28, 252-258. http:// dx.doi.org/10.1590/S0101-20612008000500038. 
Pereira; Resende

\section{Supplementary Material}

Supplementary material accompanies this paper.

Table S1. Minimum total solids content of different fruit pulps, according to Brasil (2000).

This material is available as part of the online article from http://www.scielo.br/CTA 